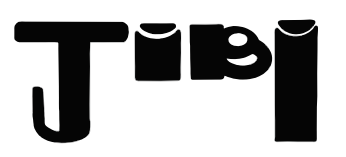

JORNAL INTERDISCIPLINAR DE BIOCIÊNCIAS

Homepage: http://www.ojs.ufpi.br/index.php/jibi

\title{
Os fatores genéticos da insônia - Uma revisão de literatura
}

\author{
The genetic factors of insomnia - a literature review
}

\author{
Guilherme Sousa Ferreira $^{1}$, Indira Maria de Almeida Barros ${ }^{1 *}$, Lyvia Ester Ferreira Xavier ${ }^{1}$ \\ ${ }^{1}$ Centro Universitário Uninovafapi
}

\begin{abstract}
A B S T R A C T
The insomnia is one of the sleep disorders characterized for the difficulty to initiate and/or maintain the sleep. This is reflected in a low quality of sleep that may cause problems during the day, such as fatigue and lack of force. Under this condition, some genetic factors are associated, among them, genes ABCC9, 5-HTT and Clock. This review has as objective the explanation about the genetic factors related to insomnia. This paper is a systematic literature review achieved through a bibliographic survey, which seeks reunite the knowledge about the characteristics of insomnia and its genetic inheritance. It was found a relevancy of valuable authorial papers for this review. Therefore, through the study of this paper, it is evident the importance of the knowledge about the genetic causes of the insomnia for the better clinical approach, once it is known the relevance of this biological mechanism.
\end{abstract}

\section{KE Y W OR D S}

Genic alteration; Sleep disorders; Insomnia; ABCC9;5-HTT; Clock

\section{RES U M O}

A insônia é um dos distúrbios do sono caracterizado pela dificuldade em iniciar ou manter o sono. Isso se reflete em um sono de baixa qualidade que pode causar problemas ao longo do dia, como cansaço e falta de energia. Sob essa condição, estão associados alguns fatores genéticos, entre eles os genes ABCC9, 5-HTT e Clock. A presente revisão de literatura tem por objetivo a explanação acerca dos fatores genéticos relacionados com o distúrbio da insônia. Tratase de uma revisão de literatura de forma sistemática, realizada por meio de um levantamento bibliográfico que procura reunir os conhecimentos sobre as características da insônia e sua herança gênica. Encontrou-se uma relevância de achados autorais valiosos para a síntese dessa pesquisa. Portanto, a partir do estudo abordado nessa revisão, torna-se evidente a importância do conhecimento das causas genéticas do distúrbio da insônia para a melhor abordagem clínica, haja vista a relevância desse mecanismo biológico.

P A L A VRAS - CHAVE

Alteração gênica; Distúrbios do sono; Insônia; ABCC9; 5-HTT; Clock

\section{INTRODUÇÃO}

Estima-se que a insônia afeta de 9 a $15 \%$ da população mundial. Denominada como um distúrbio de herança multifatorial, é caracterizada pela dificuldade de iniciar o sono ou de mantê-lo por um tempo considerado o mínimo, sem interrupção. Devido à sua relevância, várias pesquisas voltaram seu olhar para o estudo da contribuição genética na insônia, destacando os genes significativos e a participação da hereditariedade, no entanto esta revisão tem um caráter bastante relativo devido à abrangência do distúrbio (SEYFFERT et al., 2016).

Esse distúrbio pode ser classificado de acordo com o tempo que ele perdura, sendo que, quanto maior o tempo, mais crônica é a insônia. O transtorno na insônia crônica está associado a outras doenças crônicas como diabetes, AUTOR CORRESPONDENTE

Indira Maria de Almeida Barros <indira.barros@hotmail.com

Centro Universitário Uninovafapi

Rua Vitorino Orthiges Fernandes, 6123, Uruguai. CEP: 64073-505

Teresina - PI obesidade, hipertensão, doença cardiovascular, ansiedade e depressão (SEYFFERT et al., 2016).

Para Takaesu e colaboradores (2014), quando crônico, o distúrbio provoca fadiga diurna, dificuldades no desempenho cognitivo, proporcionando uma redução na qualidade de vida. Com o objetivo de estudar a insônia por um quadro geral, além de suas características específicas, pesquisas realizadas entre grupos familiares se caracterizam como principal ferramenta para a compreensão dos mecanismos genéticos e ambientais indutores da insônia. No entanto, apesar da identificação dos loci responsáveis pela regulação do sono, ainda não se encontram bem elucidados na literatura a forma como cada gene atua e de que modo a sua expressão fenotípica é influenciada pelo meio ambiente (GEHRMAN et al., 2013). 
A identificação precoce dos primeiros sinais de insônia é importante, porque essa patologia pode desencadear prejuízos sociais, profissionais, educacionais e comportamentais relevantes. No entanto, conforme Nunes e Bruni (2015), para isso, é necessário avaliar o paciente cuidadosamente na clínica, investigar o costume ao adormecer, as particularidades do sono e do acordar, além de outros fatores importantes para o diagnóstico, como o histórico familiar da doença, variabilidade de humor, hábitos noturnos (alimentação, por exemplo), presença de doenças crônicas e agudas, dentre outros.

Nesse âmbito, o sono, mecanismo intrínseco à espécie humana, representa um importante fator biológico para o restabelecimento das funções fisiológicas. Consolidação da memória, apetite, rendimento físico, qualidade no balanço energético são algumas das características que são afetadas em pacientes com insônia. Assim, um diagnóstico adequado precederá um tratamento melhor direcionado.

\section{DESENVOLVIMENTO}

Realizou-se uma revisão de literatura de forma sistemática nas bases de dados PUBMED (Público/editora MEDLINE) e CAPES (Comissão de Aperfeiçoamento de Pessoal do Nível Superior), de artigos publicados no período de 2010 a 2016 (salvo exceções de relevância considerável) escritos em inglês e em português. Os trabalhos analisados abordam a relação entre as alterações genética e os distúrbios do sono, principalmente a insônia. Para auxiliar a busca, utilizaram-se palavras-chave indexadas na Biblioteca Virtual de Saúde, tais como: alteração gênica, distúrbios do sono, insônia, GABAA,ABCC9, 5-HTT, Clock, sendo esta tríade final os nomes dos genes que norteiam o estudo.

Como resultado, obtiveram-se 27 artigos, sendo 22 do PUBMED e 5 da CAPES. O processo de organização e análise de dados foi realizado no período de fevereiro a março de 2016. A seleção dos artigos ocorreu, a priori, por meio dos resumos e pelo intervalo de tempo já relatado. Foram excluídos 9 artigos dos 27 selecionados, visto que tais não contemplavam o perfil da pesquisa.

A realização do estudo perdurou entre os meses de fevereiro a junho do ano de 2016. Elegeu-se, então, o tema da pesquisa e revisaram-se os artigos a serem empregados. Destarte, o objetivo dessa revisão de literatura sistemática foi reunir domínio intelectual para abordar a maneira como a alteração genética é capaz de interferir no sono.

A insônia pode ser definida como a dificuldade de iniciar o sono ou de mantê-lo. Além deste conceito, despertar em horários não habituais com inaptidão de retornar ao sono também pode caracterizar essa patologia. A insônia pode suscitar malefícios no funcionamento social, profissional, didático ou de idiossincrasia (NUNES; BRUNI, 2015). Conforme Wafford e Ebert (2008), esses comprometimentos, juntamente com efeitos secundários desse distúrbio, como a fadiga ao longo do dia, podem acarretar grande proporção de acidentes de trabalho.

Os processos de sono e vigília são regulados por circuitos cerebrais, dos quais são integrantes de sistemas neurais provenientes do tronco cerebral, tálamo e hipotálamo. Durante o sono normal, sistemas de excitação são regulados negativamente pela inibição das áreas préóptica ventrolateral (VLPO) e mediana (MnPO). A ativação dos centros de excitação, como o cortisol, é eficiente na conclusão do período de sono, sendo que sua atividade é regulada pelo sistema de temporização circadiano. Logo, a insônia pode ser desencadeada por uma excitação excessiva desses centros. Além disso, esse distúrbio pode ser gerado por coativação crônica de circuitos de sono e vigília durante o período de sono desejado (LEVENSON; KAY; BUYSSE, 2015).

É possível classificar a insônia em primária, nos casos em que esse evento perdura por mais de um mês sem a existência de complicações psiquiátricas; e insônia transitória, na qual é alusiva a um evento ou a acontecimentos que provoquem aumento da ansiedade, depressão ou estresse (WAFFORD; EBERT, 2008). Segundo Nunes e Bruni (2015), de acordo com a faixa etária, é possível notar diferentes motivos para o desenvolvimento da insônia, tais como: na lactação, em que há um distúrbio de sono por ingestão exagerada de líquidos durante o período noturno; em crianças na fase escolar, pode prosseguir por medo, doenças crônicas ou agudas; em adolescentes, essa patologia pode apresentarse por comorbidades psiquiátricas ou por pressão familiar. De modo similar, Barclay e outros (2013) estabeleceram efeitos idade-dependentes em relação à insônia. Por isso, deve-se avaliar o impacto que o distúrbio do sono causa na vida do paciente e como isso o aflige, além de uma investigação clínica sobre as características peculiares e rotina do ciclo sono-vigília.

Além dos processos fisiopatológicos já citados, as condições associadas ao sono podem interferir de modo a reforçar a insônia, tais como um quarto escuro e silencioso. É importante, na terapia dessa patologia, desanexar estímulos antitéticos ao sono, como ler, usar o telefone, preocupações, dentre outros (LEVENSON; KAY; BUYSSE, 2015).

Nesse contexto, pesquisas realizadas a partir de estudos familiares e em gêmeos mostraram que há fatores de predisposição para insônia em pessoas que apresentam o distúrbio. Em grupos de portadores desse distúrbio do sono, foram encontradas quantias significantes, demonstradas por Bastien e Morin (2000) e por outros pesquisadores, de pessoas que fazem parte de um grupo 
familiar cujo número de parentes com o mesmo fenótipo é considerável. Esses autores chegaram ao resultado de que $35 \%$ dos pacientes com problemas de sono possuíam parentes de primeiro ou segundo grau com esse distúrbio. Assim, os estudos de Bastien e outros (2004) e, sobretudo, o de Dauviilers e outros (2005) corroboram com a existência da influência genética familiar na insônia, sendo este último, o único estudo a excluir outros distúrbios do sono nas bases da PSG (Índice de qualidade do sono de Pittsburgh). Concomitantemente, estudos realizados por Drake e outros (2011), em gêmeos, retificam a hereditariedade dos distúrbios do sono, incluindo a insônia, além de mostrar, através de estudos com gêmeos monozigóticos (MZ), que fatores ambientais também influenciam.

A partir dessas conclusões, voltou-se o foco para a identificação dos genes que participam da determinação da insônia. Cientistas como Hamet e outros (2006); Gerhman e colaboradores (2013), após algum tempo, através de pesquisas genéticas, conseguiram entender o papel de alguns desses genes, como o gene Clock e o gene codificador da subunidade $\beta 3$ do ácido gamaaminobutírico (GABA-A). Apesar do avanço no campo genético de estudo da insônia, os resultados existentes até agora são, em sua maioria, apenas evidências que conduzem a alguns genes muito possivelmente ligado à insônia.

Outra importante descoberta genética a respeito da insônia trata da relação entre a qualidade do sono e a expressão do gene encontrado na região 5-HTTLPR no genótipo, uma vez que o alelo "small" do gene 5-HTT, achado nesta região, está associado à insônia. De acordo com Way e colaboradores (2010), os indivíduos homozigotos s/s do gene 5-HTT apresentam um desenvolvimento cerebral um pouco mais rápido que heterozigotos, o que pode levar a várias distúrbios, incluindo a insônia. De acordo com os estudos de Brummetet e colaboradores (2007), a conexão entre qualidade de sono e estresse do dia a dia é mediada pela região 5-HTLPR, de forma que os homozigotos para o alelos demonstram a pior qualidade de sono, avaliada por PSQI.

Entender o papel do polimorfismo do transportador de serotonina 5-HTLPR possibilita um ponto de vista novo do qual se permite mensurar a vulnerabilidade. De acordo com Harvey e colaboradores (2014), isso acontece, porque, primeiramente, o 5-HTLPR pode influenciar em uma resposta psicológica crescente ao estresse e, segundo, porque ele também é capaz de interferir na personalidade. Assim, situações que afetem estes dois quesitos contribuem mais ativamente em pessoas predispostas a ter esse gene.
Ainda sobre o gene 5-HTLPR, foi descoberto que, por meio de fatores psicobiossociais, ele influencia na qualidade e na duração do sono, seja mediando um aumento de uma resposta psicológica em nível de estresse ou interagindo com a personalidade. $\mathrm{Na}$ verdade, segundo Harvey e colaboradores (2014), a resposta ao estresse é o centro da maioria dos modelos propostos para explicar distúrbios do sono, principalmente a insônia, em que esse importante fator ambiental está ligado à genética.

Além disso, destaca-se também o gene ABCC9. Uma variação intrônica neste gene ( $r$ 11046205; P = 3,99 x 10 ${ }^{8}$ ) explica cerca de $5 \%$ de variações da duração do sono. $\mathrm{O}$ ABCC9 codifica a subunidade SUR2 do canal de potássio sensível à $\mathrm{ATP}\left(\mathrm{K}_{\mathrm{ATP}}\right)$ e realiza atividade semelhante a um sensor de energia no metabolismo intracelular (ALLEBRANDT et al., 2013).

$\mathrm{O} \mathrm{K}_{\mathrm{ATP}}$ representa um sensor metabólito ao estresse e à hipóxia, auxilia na regulação da unidade neurovascular (NELSON et al., 2015). Logo, o gene ABCC9 e o seu componente polipeptídico, SUR2, ocupam uma posição intrigante para a vasorregulação no cérebro. Como a maioria das células do cérebro (neurônios, astrócitos, oligodentrócitos, micróglia, entre outras) expressa o produto polipeptídico, variações nos genes estão relacionadas com distúrbios que afetam a região.

É válido ressaltar que a função bioquímica do canal de $\mathrm{K}_{\mathrm{ATP}}$ ainda não é totalmente compreendida. Contudo, valiosos estudos experimentais apontam algumas funções para esses canais como atividades relacionadas ao desenvolvimento e ao metabolismo celular. Isso corrobora para a relação entre o canal $\mathrm{K}_{\mathrm{ATP}}$ e o gene ABCC9 no distúrbio da insônia (NELSON et al., 2015).

Apesar da forte contribuição do gene para o distúrbio, ele não é fator determinante no estabelecimento da gravidade da condição. A rotina e o estilo de vida constituem duas outras situações que favorecem a doença. Segundo Takaesuet e outros (2014), o estabelecimento de uma adequada estratégia de tratamento proporciona uma melhoria desejável. Para isso, as benzodiapezinas (BZD) constituem importante opção no tratamento do distúrbio. Contudo, em longo prazo, podem causar intolerância e dependência.

\section{CONCLUSÃO}

A insônia é uma doença de herança multifatorial, na qual se observa a contribuição genética a partir do genótipo e da ação hereditária. A evidenciação dos genes Clock, gene codificador de GABA-A, gene 5-HTT e gene ABCC9, pelas pesquisas abordadas nesta revisão, é importante para compreensão da influência que eles exercem na complexidade dos aspectos constituintes desse distúrbio, tais como qualidade do sono, vulnerabilidade à 
disfunção, predisposição, duração do sono e outros. Contudo, ainda há a necessidade de estudos com fenotipagem mais consolidada sobre a insônia para melhor esclarecimento acerca desse tema. Não obstante haja o conhecimento sobre a expressão fenotípica dos genes envolvidos, o ambiente ainda é uma influência não muito explanada na literatura, mas que age em situações que propiciam o desenvolvimento ou agravamento dessa enfermidade.

Destaca-se uma época favorável para maiores apurações acerca da insônia, levando em consideração as técnicas modernas da genética molecular atual. Por isso, espera-se um prosseguimento das pesquisas relacionadas às características fenotípicas da insônia, para evolução dos conhecimentos genéticos e fisiopatológicos desse distúrbio, além do progresso no desenvolvimento de medicamentos eficazes que possam promover melhor qualidade de vida, sem causar dependência aos pacientes.

\section{REFERÊNCIAS}

KALLEBRANDT, K V. et al. KATP gene effect on sleep duration: from genome-wide association studies to function in Drosophila. Molecular Psychiatry. v. 18, p. 122-132, 2013.

BASTIEN, C. H.; MORIN, C. M. Familial incidence of insomnia. J. Sleep Res. v. 9, n.1, p. 49-54, 2000.

BASTIEN, C. H.; VALLIERES, A.; MORIN, C. M. Precipitating factors of insomnia. Behave Sleep Med. v.2, p. 50-62, 2004.

BARCLAY, N. L.; GREGORY, A. M. Quantitative genetic research on sleep: a review of normal sleep, sleep disturbance and associated emotional, behavioural, and health-related difficulties. Sleep Medicine Reviews. v. 17, p. 29-40, 2013.

BRUMMET, B. H. et al. Sleep quality varies as a function of 5HTLPR genotype and stress. Psychosom. Med. v. 69, 2007.

DAUVILLIERS, Y. et al. Family studies in insomnia. J. Psychosom. Res. v. 58, 2005

DRAKE, C. L. et al, Thomas. Sleep reactivity and Insomnia: genetic and environmental Influences. Sleep. v. 34, n. 9, p. 1179 1188, 2011.

GEHRMAN, P. et al. Genetics of insomnia. Sleep Med. Clinic. v. 6, p. 192-202, 2011.

GEHRMAN, P. R.; BYRNE, E.; PFEIFFENBERGER, C. The role of genesin the insomnia phenotype. Sleep Med. Clinic. v. 8, p. 323-331, 2013.

HAMET, P.; TREMBLAY, J. Genetics of the sleep-wake cycle and its disorders. Metabolism. v. 55, p. 7-12, 2006.

HARVEY, C.; GERHMAN, P.; ESPIE, C. A. Who is predisposed to insomnia: a review of familial aggregation, stress reactivity, personality and coping style. Sleep Medicine Reviews. v. 18, p. 237-247, 2014.
LEVESON, J. C.; KAY, D. B.; BUYSSE, D. J. The Pathophysiology of Insomnia. Chest. v.147, n.4, p.1179-1192, 2015.

NELSON, P. T. et al. ABCC9/SUR2 in the brain: Implications for hippocampal sclerosis of aging and a potential therapeutic target. Ageing Research Reviews. v. 24, 2015. p. 111-125, 2015.

NUNES, M. L.; BRUNI, O. Insônia na infância e adolescência: aspectos clínicos, diagnóstico e abordagem terapêutica. Jornal de Pediatria. v. 91, n. 6, p. S26-S35, 2015.

SEYFFERT, M. et al. Internet-Delivered Cognitive Behavioral Therapy to Treat Insomnia: A systematic Review and MetaAnalysis. Plos One. v.11. n. 2, 2016.

TAKAESU, Y. et al. Factors Associated with Long-Term Use of Hypnotics among Patients with Chronic Insomnia. Plos one. v. 9. n. 9.2014.

WAFFORD, K. A.; EBERT, B. Emerging anti-insomnia drugs: tackling sleeplessness and the quality of wake time. Nature Reviews. v.7, p. 530-540, 2008.

WAY, B. M.; TAYLOR, S. E.; The serotonin transporter promoter polymorphism is associated with cortisol response to psychosocial stress. Biol. Psychiatry. v. 67, p. 487, 2010. 